Health \& Medicine | Nestlé

\section{When grow healthy rhymes with grow happy}

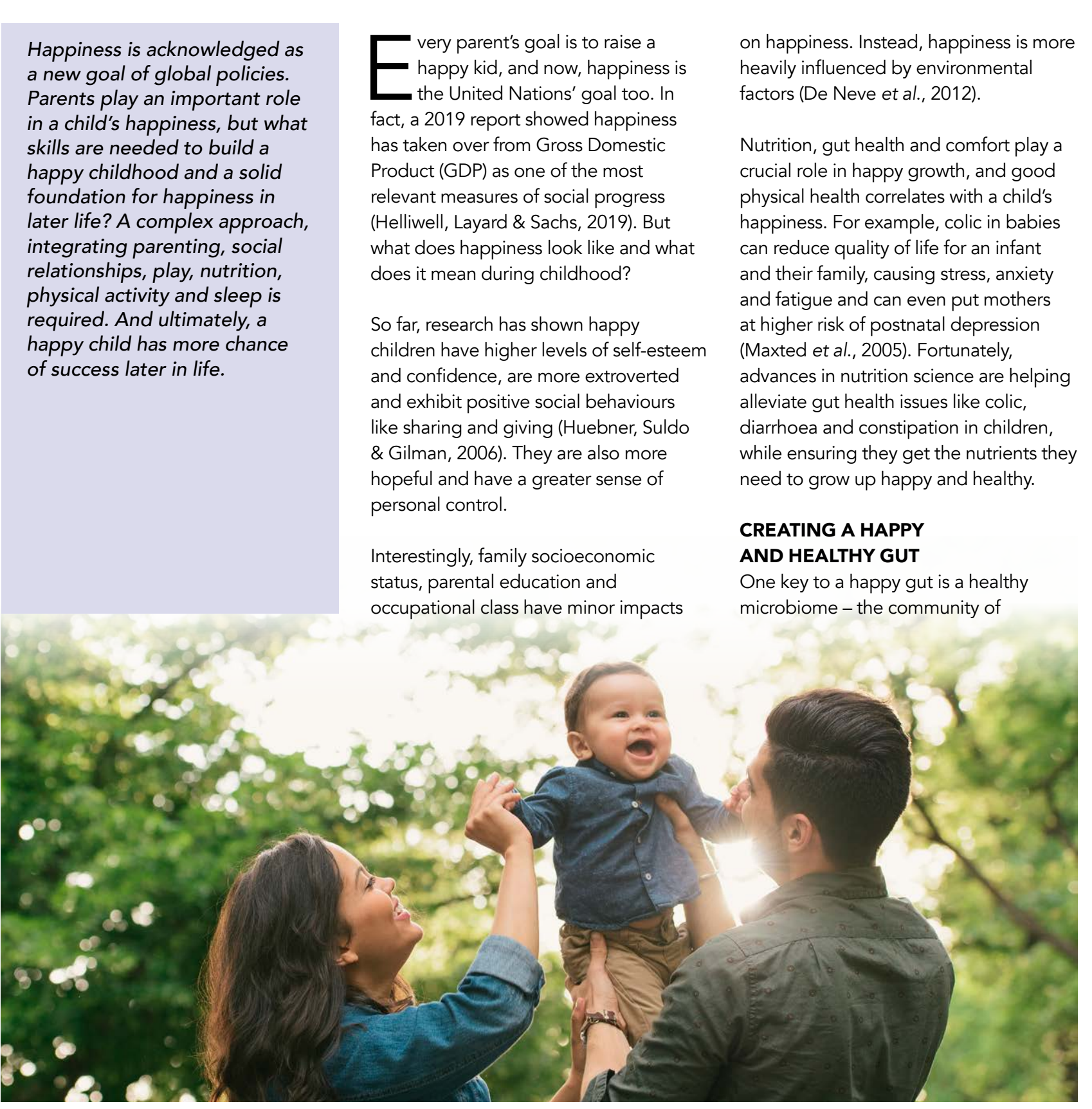

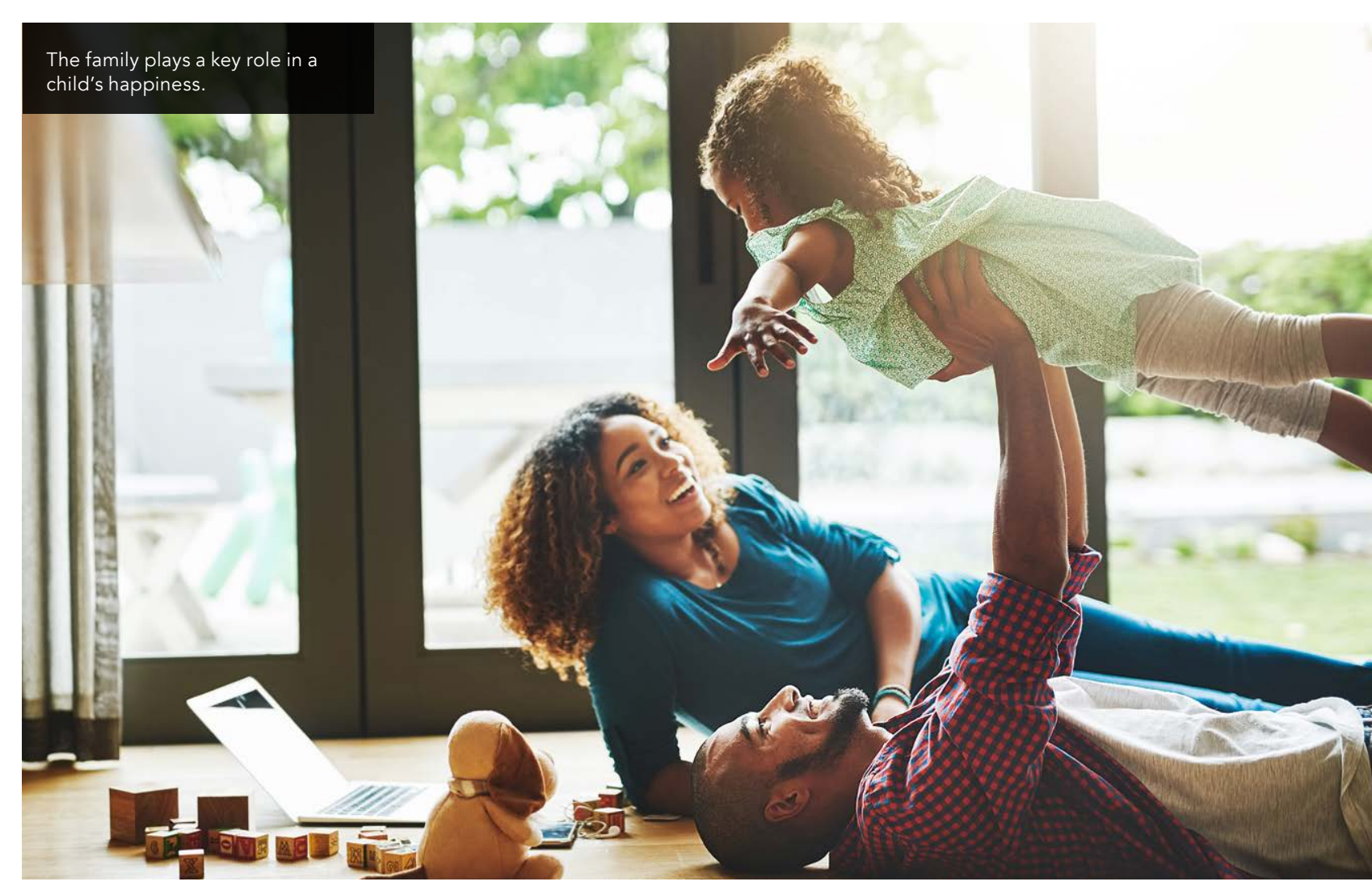

bacteria, fungi and other microorganisms help relieve constipation by drawing naturally found in the intestines - that water into the intestine and softening help break down nutrients and promote stools. Stool consistency can also be gut function. Among the best studied community members is Lactobacillus reuteri, a probiotic bacterium that can be found in human milk. This beneficial probiotic may help to relieve constipation, regurgitation and diarrhoea in infants (Indrio et al., 2014; GutierrezCastrellon, 2014). and can even help It can also allevite colic discomfort. reducing allow family's quality of life (Savino et al, 2007; Bellaiche et al., 2018).

\section{AN EASIER "WHEY" TO DIGEST} Human milk is filled with nutrients including proteins, fats, carbohydrates, vitamins and minerals. However, not all proteins have the same digestibility. For pome infants may struggle to digest a protein called casein, potentially

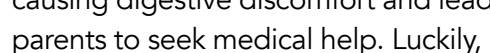
parents to seek medical help. Luckly, proteins which do not clot in the whey and are much easier to digest.

Other ingredients with beneficial influences on gut comfort include also be and lactose, designed to help infants ormula; some have a specific nutritional comfort and overall happy growth profile supporting softer stool formation through improved digestion, gut health closer to that of breastfed babies (Infante et al., 2011). Knowing this, Nestle developed a set of According to Nestlé, most traditiona

...happy children have higher levels of self-esteem and confidence, are more extroverted and exhibit positive social behaviours..

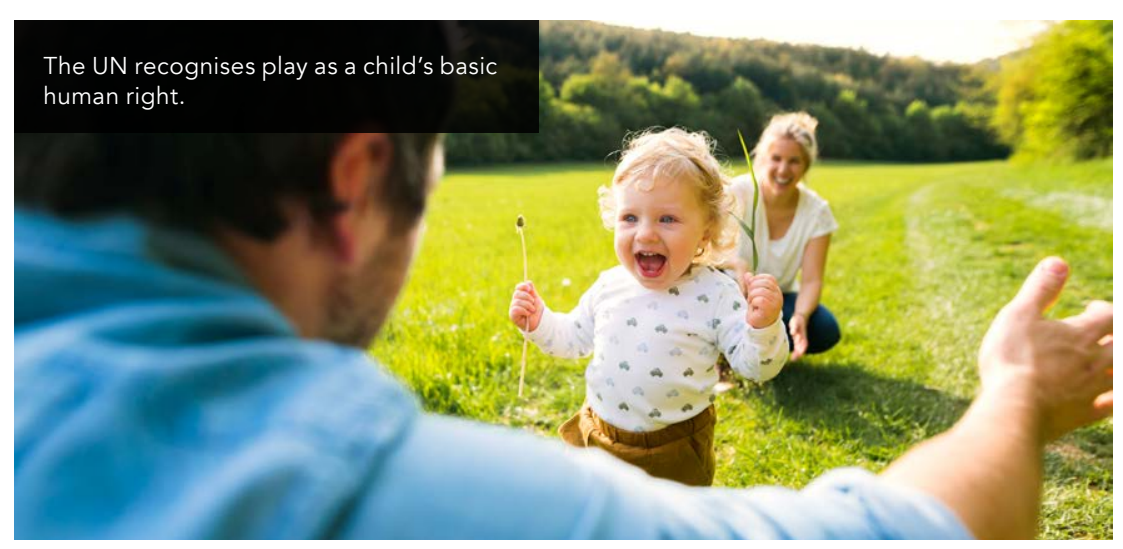




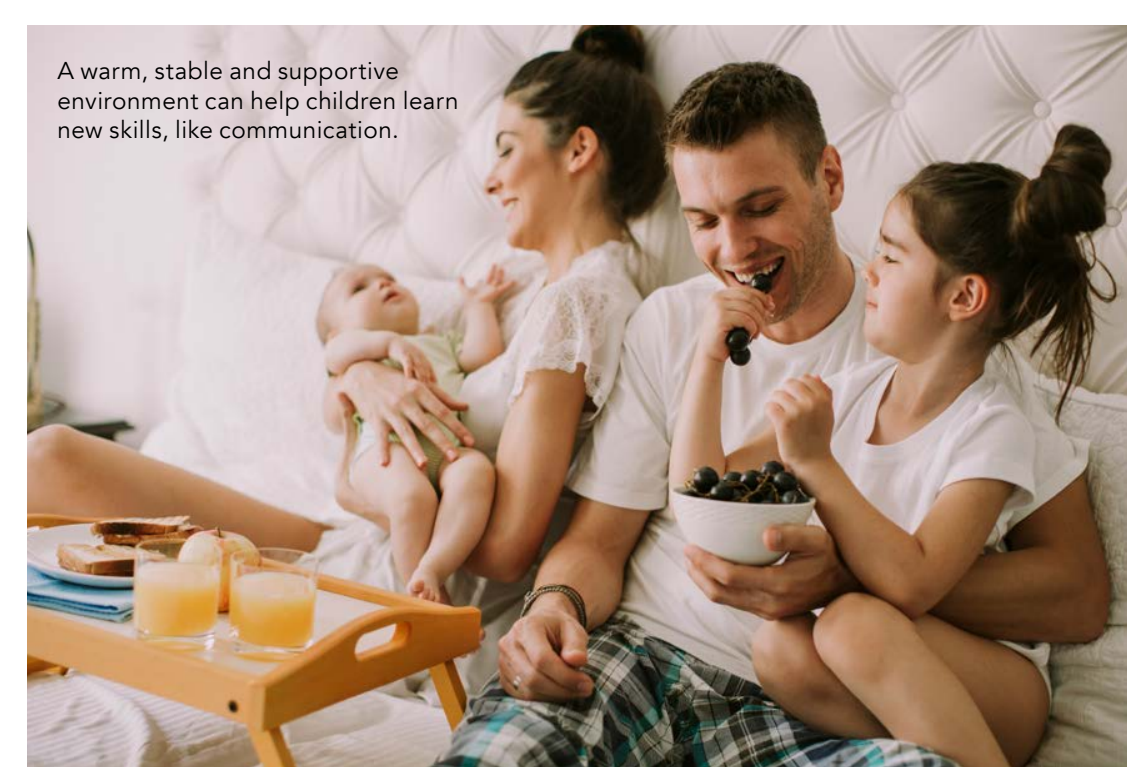

Nestlé has created ... formulae based

on human milk, which support child development and improve quality of life for infants and their families.

chain saturated fatty acids (LCSFA) in position 1-3. These specific fatty acids (sn1 - sn3) typically bind calcium in the gut to form "calcium-fatty acid soaps", reducing calcium absorption and hardening the stool. Interfering with this process helps calcium absorption, which is important for bone health, and impacts on overall infant comfor happy growth and health.

As a result, Nestlé reduced the number of LCSFAs in their formulae so that it is functionally comparmulae so that it is allowing for better fat and calcium

absorption, and softer stools. The latter is particularly important as around $50 \%$ of children develop constipation Benninga \& Di Lorenzo, 2006).

\section{SUPPORTING HAPPY GROWTH} Nutrition, gut health and comfort are critical for kids' development, happiness and quality of life, but they aren't the only things.

Research has shown that parenting style and social relationships can significantly impact children's security

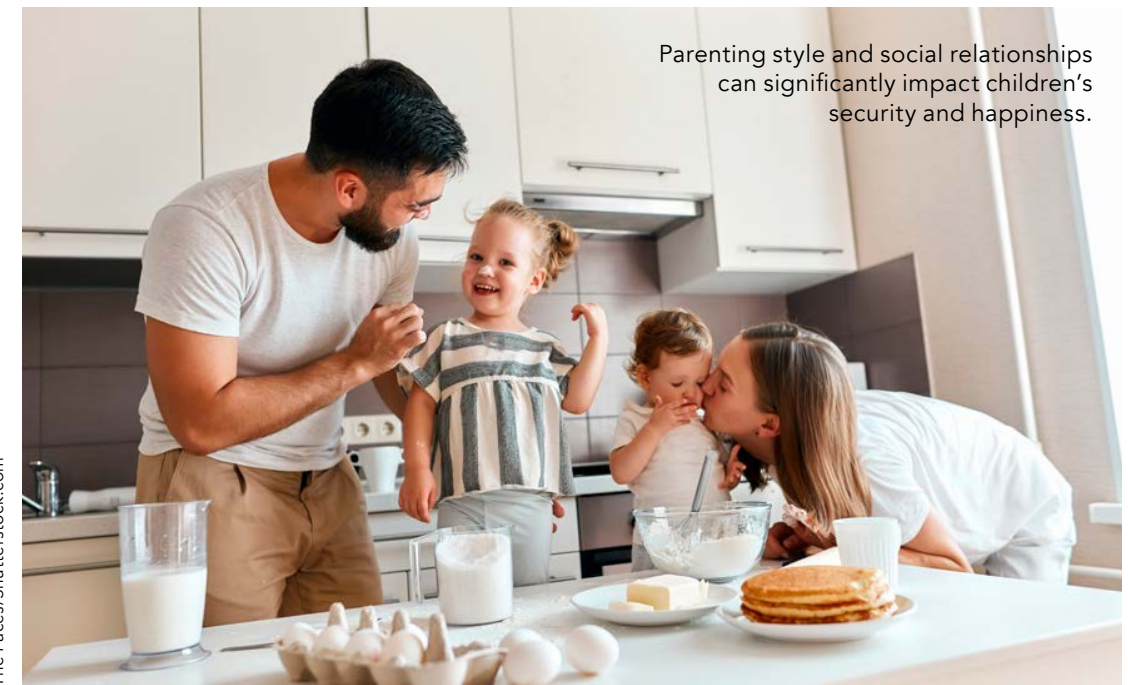

BREASTFEEDING IS BEST FOR BABIES and happiness (Loton \& Waters, 2017) Growing up in a warm, stable and and boundaries can help hildren form deeper, respectful relationships with their parents. It also helps children learn new skills, like communication, behaviour control and emotional intelligence (Shirtcliff et al., 2017). This gives them confidence and helps them develop strong friendships later in life.

Play is another key element of happiness and is crucial for physical emotional, social and mental development. It's so important that the UN recognises it as a child's basic human right (Office of the UN High Commissioner Human Rights, 1989). Kids can engage in a range of play, 'including 'ree and unstructured", 'educational'. These foster creativity, 'elf-esteem, resilience, cognitive development, academic success and wellbeing (Pellis \& Pellis, 2007).

It goes without saying that physical activity is important for child development, self-efficacy and socia influence (Gray, 2011). Here, parents can encourage kids to play a sport, invest in more outdoor family activities or, if children do play video games, select ones with exercise components.

Finally, parents need to make sure kids get enough sleep to perform their best during the day. Developing good sleeping habits - such as electronic devices - can help improve children's behaviour and wellbeing (Hale et al., 2011).

\section{TYING IT ALL TOGETHER} Raising a happy kid is every parent's goa and with happiness bringing so many there are plenty of ways to support happy growth, whether it's engaging in play, encouraging social interaction, or helping kids get the nutrition they need for healhy development. Nestles formulae, such as LACTOGEN \& NESTOGEN ${ }^{\boxplus}$, support parents and kids in this journey, precific proteins, fats and specific proteins, fats and probiotics needed for a happy gut, happy grow

\section{Behind the Research}

E: Sanjeev.Ganguly@Nestlé.com T: +41 219241245 W: https://www.nestlenutrition-institute.org/

Detail

Sanjeev Ganguly
Head-Global Medical Affairs I Nutrition SBU

Société des Produits Nestlé S.A

Bio

References

- Bellaiche, M. et al. (2018). Multiple functional gastrointestinal their quality of life. Acta Paediatr., 107, 1276-1282.

- De Neve, J-E., Christakis, N.A., Fowler, J.H \& Frey, B.S. (2012). Genes, Economics and Happiness. J Neurosci Psychol Econ, 5(4), 193-211. Avallable at: https://dol.org/10.1037/a0030292

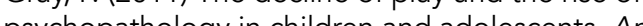
Journal of Play, 3443-463. - Gutierrez-Castrellon P., et al. (2014). Diarrhea in Preschool Children and Lactobacillus Reuteri: A Randomized Controlled Trial. Pediatrics, 133(4), e904-e909. AR

(201). A Algitudi al study of preschoolers' language-based Family Psychology, 25, 423.

- Helliwell, J., Layard, R., \& Sachs, J. (2019). World Happiness Report, New York: Sustainable Development Solutions Network - Huebner, E.S., Suldo, S.M. \& Q Gilman, R. (2006). Life needs (II: Development prevention and interventdren's (357-368). National Association of School Psychologists. -Indrio, F., Di Mauro, A., Riezzo, G., Civardi, E., Intini, C.. Corvaglia, L., Ballardini, E., Bisceglia, M., Cinquetti, M., Brazzoduro, E., Del Vecchio, A., Tafuri, S. \& Francavilla, R. colic, Prophylatic use of a problotic in the prevention of clinical trial. JAMA Pediatr. 168(3), 228-233.

- Infante, D., Segarra, O., Redecillas, S., Alvarez, M. \& Miserachs, M. (2011). Modification of stool's water content

in constipated infants: management with an adapted infant
- Loton, D.J. \& Waters, L.E. (2017). The Mediating Effect of Parenting, Happiness and Psychological Distress in Teens.

Frontiers in Psychology, 8, 1707.
- Maxted, A.E., Dickstein, S., Miller-Loncar, C., High, P., Spritz, B., Liu, J. \& Lester, B.M. (2005). Infant Colic and Maternal Available at: https://doi org/10.1002/imbi 20035-68. - Office of the UN High Commissioner Human Rights. (1989). Convention on the Rights of the Child. Available at: https:// www.ohchr.org/en/professionalinterest/pages/crc.aspx [Accessed 22/04/2020] -Pellis, S.M. \& Pellis, V.C. (2007). Rough-and-tumble play and the development of the social brain. Current Directions https://doi.org/10.1111/j.1467-8721.2007.00483.x - Savino, F., Pelle, E., Oggero, R. \& Miniero, R. (2007) Lactobacilius reuteri (American Type Culture Collection Strain A prospective simethicone in the treatment of infantile colic - Shrirtliff, EA A Skinner, M. L Obasi, EM. \& Haggerty KP. (2017). Positive parenting predicts cortisol functioning six years later in young adults. Developmental Science, 20(6). - Valeur, N., Engel, P., Carbajal, N., Connolly, E. \& Ladefoged, K. (2004). Colonization and immunomodulation gastrointestinal tract. Appl Environ Microbiol, $70(2)$

1176-1181

- van den Berg, M.M., Benninga M.A. \& Di Lorenzo, C. (2006). Epidemiology of childhood constipation: a systematic review.

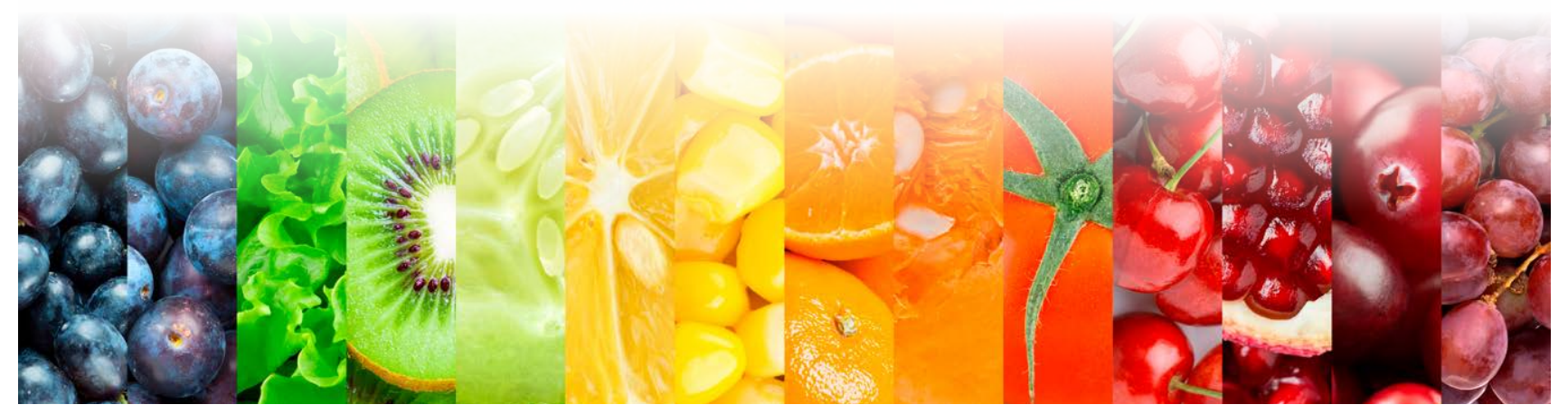

